\title{
The Effect of Annealing Temperature on the Phase Constitution and Magnetic Properties of the $\mathrm{Pr}_{8} \mathrm{Dy}_{1} \mathrm{Fe}_{60} \mathrm{Co}_{7} \mathrm{Mn}_{6} \mathrm{~B}_{14} \mathrm{Zr}_{1} \mathrm{Ti}_{3}$ Alloy Ribbons
}

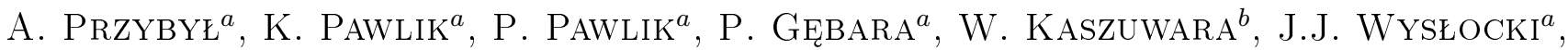 \\ AND K. FILIPECKA ${ }^{a}$ \\ ${ }^{a}$ Institute of Physics, Częstochowa University of Technology, al. Armii Krajowej 19, 42-200 Częstochowa, Poland \\ ${ }^{b}$ Faculty of Materials Science and Engineering, Warsaw University of Technology, \\ Wołoska 141, 02-507 Warsaw, Poland
}

(Received February 2, 2015)

\begin{abstract}
Melt-spun ribbons were produced from the $\operatorname{Pr}_{8} \mathrm{Dy}_{1} \mathrm{Fe}_{60} \mathrm{Co}_{7} \mathrm{Mn}_{6} \mathrm{~B}_{14} \mathrm{Zr}_{1} \mathrm{Ti}_{3}$ base alloy at the surface velocity of the cooper wheel of $30 \mathrm{~m} / \mathrm{s}$. The studies showed amorphous structure of ribbons and their soft magnetic properties. $\mathrm{X}$-ray diffraction was used to determine phase constitution of all obtained samples. Annealing of ribbons caused formation of nanocomposite structure, which was a result of coexistence of hard magnetic $\mathrm{RE}_{2}(\mathrm{Fe}, \mathrm{Co}){ }_{14} \mathrm{~B}$ and soft magnetic $\alpha$-Fe phases. Basic magnetic properties such as: coercivity ${ }_{J} H_{\mathrm{c}}$, remanence $J_{\mathrm{r}}$ and maximum energy product $(B H)_{\max }$ were determined from the measured hysteresis loops. The microstructure of selected specimens was observed by transmission electron microscopy technique.
\end{abstract}

DOI: 10.12693/APhysPolA.128.94

PACS: 75.20.En, 91.60.Pn

\section{Introduction}

In the past decades the $\mathrm{Nd}-\mathrm{Fe}-\mathrm{B}$ permanent magnets have been widely investigated due to the their excellent magnetic properties $[1,2]$ and potential applications in instruments such as magnetic resonance imaging (MRI) devices and voice coil motors (VCM) for hard disc drives (HDD) [3]. Despite the similarities between praseodymium and neodymium in the elemental state (both of them [4] can form the $\mathrm{RE}_{2} \mathrm{Fe}_{14} \mathrm{~B}$ compounds [5]), the $\mathrm{Pr}-\mathrm{Fe}-\mathrm{B}$ system did not attracted similar attention as the neodymium system. The excellent magnetic properties of $\mathrm{Nd}_{2} \mathrm{Fe}_{14} \mathrm{~B} / \alpha$-Fe and $\operatorname{Pr}_{2} \mathrm{Fe}_{14} \mathrm{~B} / \alpha$ Fe nanocomposite permanent magnets arise from the exchange interaction between magnetically hard and soft phases. The high anisotropy hard magnetic phase is responsible for high coercivity while the soft magnetic phase causes increase of magnetization. Exchange interactions between grains of hard and soft magnetic phases cause that the magnetization vector of the soft magnetic phase is exchange coupled with those of the hard magnetic phase. It is difficult to exactly calculate the interactions between grains, due to highly complicated microstructure in this kind of materials. Both the chemical composition and processing technique, can affect the magnetic properties and their microstructure [6-10]. An experimental method allowing to determine the nature of these intergrain interactions and their effect on the magnetic properties, $\delta M$ plot technique is commonly adopted [6, 11-13].

Therefore, in this study, the effects of heat treatment on the phase constitution, magnetic properties and exchange interactions of the $\operatorname{Pr}_{8} \mathrm{Dy}_{1} \mathrm{Fe}_{60} \mathrm{Co}_{7} \mathrm{Mn}_{6} \mathrm{~B}_{14} \mathrm{Zr}_{1} \mathrm{Ti}_{3}$ produced by melt spinning technique, are investigated.

\section{Experimental material and methods}

The ingot samples of nominal composition $\mathrm{Pr}_{8} \mathrm{Dy}_{1} \mathrm{Fe}_{60} \mathrm{Co}_{7} \mathrm{Mn}_{6} \mathrm{~B}_{14} \mathrm{Zr}_{1} \mathrm{Ti}_{3}$ were produced by arc-melting of high purity constituent elements with addition of pre-alloyed $\mathrm{Fe}-\mathrm{B}$, under an argon atmosphere. To homogenize the alloy, the samples were re-melted several times. The ribbon samples were prepared by single wheel melt-spinning technique under the Ar protective atmosphere. The linear speed of the copper wheel surface of $30 \mathrm{~m} / \mathrm{s}$ was used in the process. Subsequently, the ribbon samples were sealed off in a quartz tube under a low pressure of argon to maintain the purity of atmosphere during heat treatment. In order to obtain a nanocrystalline microstructure, the samples were annealed at various temperatures ranging from $923 \mathrm{~K}$ to $1023 \mathrm{~K}$ for $5 \mathrm{~min}$, and subsequently rapidly cooled in water. The phase structure analysis of ribbons was studied using Bruker D8 Advance diffractometer with $\mathrm{Cu} K_{\alpha}$ radiation. The room temperature hysteresis loops were measured by LakeShore 7307 vibrating sample magnetometer at external magnetic fields up to $2 \mathrm{~T}$. The minor hysteresis loops were measured to obtain the field dependences of remanence $J_{\mathrm{r}}$ and coercivity ${ }_{J} H_{\mathrm{c}}$. The series of recoil curves were measured for the initially saturated samples and for the thermally demagnetized specimens.

\section{Results and discussion}

The X-ray diffraction (XRD) patterns measured for $\mathrm{Pr}_{8} \mathrm{Dy}_{1} \mathrm{Fe}_{60} \mathrm{Co}_{7} \mathrm{Mn}_{6} \mathrm{~B}_{14} \mathrm{Zr}_{1} \mathrm{Ti}_{3}$ alloy ribbons in as-cast state are shown in Fig. 1. The measurements were carried out on both surfaces of the ribbons: on the side in thermal contact with copper roll during melt-spinning 
(bottom side) and on free surface of the ribbon (top side). Lack of peaks on the wide bumps on XRD patterns measured for both side suggest their fully amorphous structure.

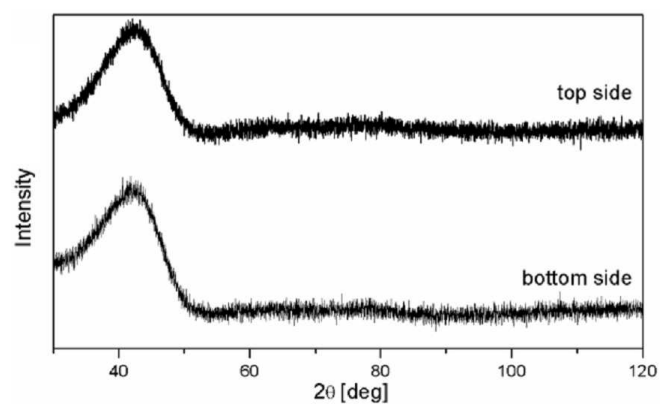

Fig. 1. X-ray diffraction patterns measured for $\mathrm{Pr}_{8} \mathrm{Dy}_{1} \mathrm{Fe}_{60} \mathrm{Co}_{7} \mathrm{Mn}_{6} \mathrm{~B}_{14} \mathrm{Zr}_{1} \mathrm{Ti}_{3}$ alloy ribbon samples in as-cast state.

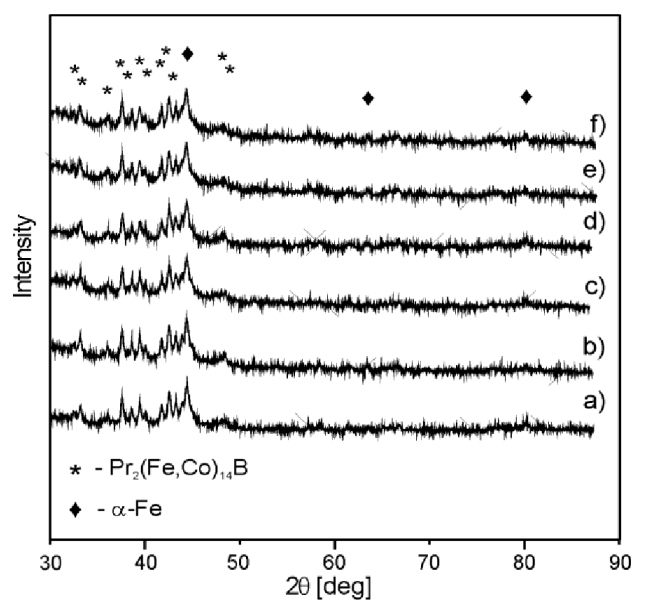

Fig. 2. X-ray diffraction patterns measured for $\mathrm{Pr}_{8} \mathrm{Dy}_{1} \mathrm{Fe}_{60} \mathrm{Co}_{7} \mathrm{Mn}_{6} \mathrm{~B}_{14} \mathrm{Zr}_{1} \mathrm{Ti}_{3}$ alloy ribbon samples annealed at (a) $923 \mathrm{~K}$, (b) $943 \mathrm{~K}$, (c) $963 \mathrm{~K}$, (d) $983 \mathrm{~K}$, (e) $1003 \mathrm{~K}$, (f) $1023 \mathrm{~K}$ for $5 \mathrm{~min}$.

The XRD patterns measured for the $\mathrm{Pr}_{8} \mathrm{Dy}_{1} \mathrm{Fe}_{60} \mathrm{Co}_{7} \mathrm{Mn}_{6} \mathrm{~B}_{14} \mathrm{Zr}_{1} \mathrm{Ti}_{3}$ alloy ribbon samples annealed at temperatures from $923 \mathrm{~K}$ to $1023 \mathrm{~K}$ for 5 min, are shown in Fig. 2. The short time annealing for 5 min at $923 \mathrm{~K}$ and higher temperatures led to nucleation and growth of the crystalline phases. The crystalline phases observed for the all annealed ribbons were: the hard magnetic $\mathrm{Pr}_{2}(\mathrm{Fe}, \mathrm{Co})_{14} \mathrm{~B}$ and soft magnetic $\alpha$-Fe. Nanocrytalline microstructure of annealed samples was confirmed by transmission electron microscopy (TEM) studies (Fig. 3).

In Fig. 3 the TEM micrographs and corresponding diffraction patterns for $\mathrm{Pr}_{8} \mathrm{Dy}_{1} \mathrm{Fe}_{60} \mathrm{Co}_{7} \mathrm{Mn}_{6} \mathrm{~B}_{14} \mathrm{Zr}_{1} \mathrm{Ti}_{3}$ melt-spun ribbons annealed at $943 \mathrm{~K}$ (a) and $983 \mathrm{~K}(\mathrm{~b})$ are shown. The heterogeneous microstructure of the sample annealed at $943 \mathrm{~K}$ with small grains of average size ranging from $20 \mathrm{~nm}$ to $40 \mathrm{~nm}$ embedded within the amorphous matrix was revealed. Occurrence of the amor-

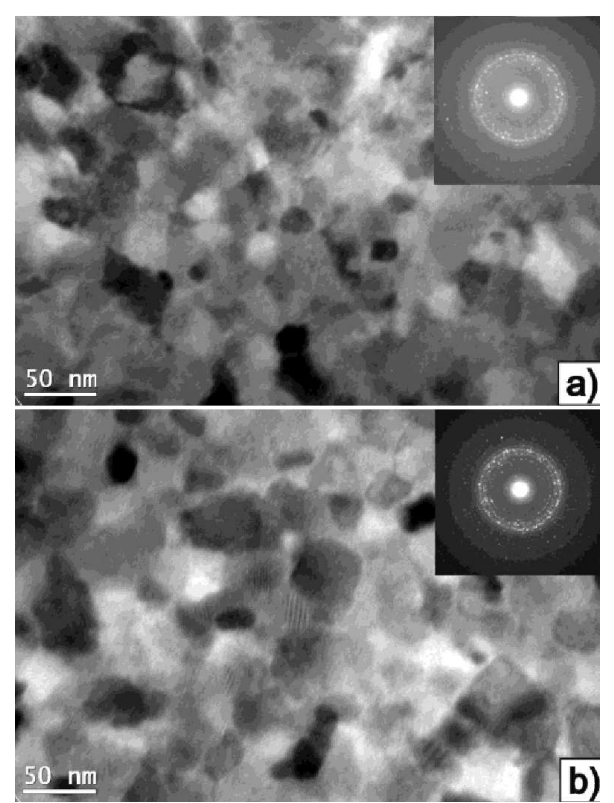

Fig. 3. TEM micrograph of the $\mathrm{Pr}_{8} \mathrm{Dy}_{1} \mathrm{Fe}_{60} \mathrm{Co}_{7} \mathrm{Mn}_{6} \mathrm{~B}_{14} \mathrm{Zr}_{1} \mathrm{Ti}_{3}$ melt-spun ribbons annealed at $943 \mathrm{~K}(\mathrm{a}), 983 \mathrm{~K}$ (b) for $5 \mathrm{~min}$ and corresponding diffraction pattern.

phous phase in this sample was confirmed by XRD studies. Heat treatment of the alloy at higher temperature causes slight growth of crystallites. For ribbon annealed at $983 \mathrm{~K}$ average grain size ranges from $30 \mathrm{~nm}$ to $50 \mathrm{~nm}$. Furthermore annealing at this temperature led to optimal magnetic properties (Table).

TABLE

Magnetic parameters: the coercivity, the remanence, maximum energy product $(B H)_{\max }$ and reduce remanence $J_{\mathrm{r}} / J_{\mathrm{s}}$ for all annealed samples.

\begin{tabular}{c|c|c|c|c}
\hline \hline $\begin{array}{c}\text { Annealing } \\
\text { temperature } \\
{[\mathrm{K}]}\end{array}$ & $\begin{array}{c}{ }_{J} H_{\mathrm{c}} \\
{[\mathrm{kA} / \mathrm{m}]}\end{array}$ & $\begin{array}{c}J_{\mathrm{r}} \\
{[\mathrm{T}]}\end{array}$ & $\begin{array}{c}(B H)_{\max } \\
{\left[\mathrm{kJ} / \mathrm{m}^{3}\right]}\end{array}$ & $J_{\mathrm{r}} / J_{\mathrm{s}}$ \\
\hline 923 & 901 & 0.44 & 29 & 0.69 \\
\hline 943 & 945 & 0.38 & 22.4 & 0.68 \\
\hline 963 & 780 & 0.41 & 29.6 & 0.68 \\
\hline 983 & 925 & 0.36 & 43.3 & 0.69 \\
\hline 1003 & 868 & 0.52 & 38.3 & 0.71 \\
\hline 1023 & 747 & 0.64 & 31.5 & 0.69
\end{tabular}

Magnetic measurements carried out on ribbons in ascast state (Fig. 4a) have shown their soft magnetic properties, which also confirms their amorphous structure (Fig. 1). Heat treatment led to the improvement of the magnetic properties (Fig. 4b).

With increasing annealing temperature, an increase of remanence $J_{\mathrm{r}}$ and saturation polarization, while decrease of coercivity field ${ }_{J} H_{\mathrm{c}}$ was observed (Fig. 5). The highest values of remanence $J_{\mathrm{r}}$ and saturation polarization were measured for sample annealed at $1023 \mathrm{~K}$. At the major hysteresis loops, characteristic kinks on demagnetization 


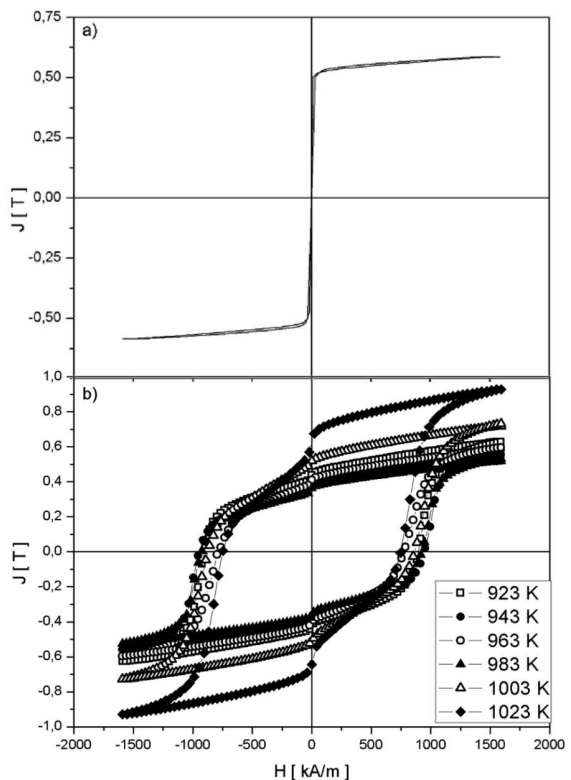

Fig. 4. Major hysteresis loops measured for the $\operatorname{Pr}_{8} \mathrm{Dy}_{1} \mathrm{Fe}_{60} \mathrm{Co}_{7} \mathrm{Mn}_{6} \mathrm{~B}_{14} \mathrm{Zr}_{1} \mathrm{Ti}_{3}$ alloy in the form of ribbons in as-cast state (a) and annealed at $923 \mathrm{~K}$ and $1023 \mathrm{~K}$ for $5 \mathrm{~min}(\mathrm{~b})$.

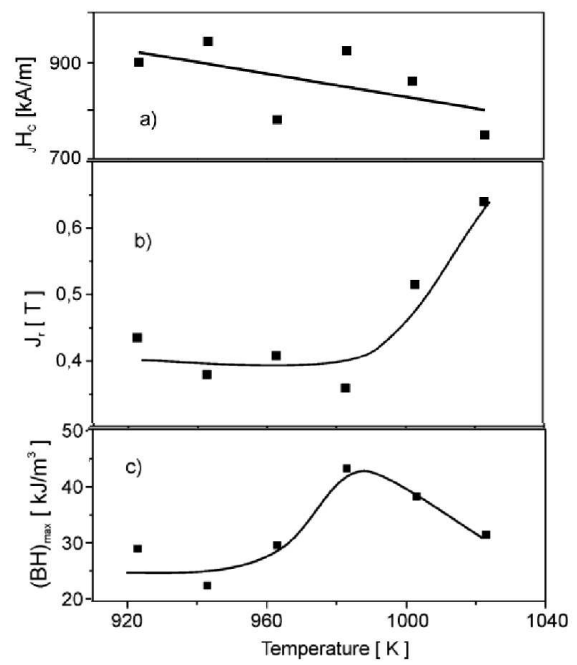

Fig. 5. Coercivity ${ }_{J} H_{\mathrm{c}}$ (a), remanence $\mathrm{J}_{\mathrm{r}}$ (b) and maximum energy product $(B H)_{\max }(\mathrm{c})$ vs. the annealing temperature $T$ measured for ribbons of the $\mathrm{Pr}_{8} \mathrm{Dy}_{1} \mathrm{Fe}_{60} \mathrm{Co}_{7} \mathrm{Mn}_{6} \mathrm{~B}_{14} \mathrm{Zr}_{1} \mathrm{Ti}_{3}$ alloy.

curves around $H=0$ was observed (Fig. 4b) which may indicate a presence of soft magnetic phase.

The basic magnetic properties of the $\mathrm{Pr}_{8} \mathrm{Dy}_{1} \mathrm{Fe}_{60} \mathrm{Co}_{7} \mathrm{Mn}_{6} \mathrm{~B}_{14} \mathrm{Zr}_{1} \mathrm{Ti}_{3}$ ribbon samples were collected in Table. The enchancement of remanence $\left(J_{\mathrm{r}} / J_{\mathrm{s}}>0.5\right)$ suggest exchange-coupling in the ribbons [7]. In order to prove the existence of exchangecoupling the calculation of $\delta M$ plots $(\delta M(H))$ [14] were carried out using formula

$$
\delta M=m_{\mathrm{d}}(H)-\left[1-2 m_{\mathrm{r}}(H)\right],
$$

where $m_{\mathrm{d}}$ is reduced demagnetization remanent magnetization and $m_{\mathrm{r}}$ is the reduced isothermal remanent magnetization. The positive $\delta M$ values indicate the existence of exchange-coupling between magnetically hard grains or between two kinds of phases [15]. The magnitude of positive $\delta M$ represents the strength of intergranular exchange-coupling interaction. The negative values of $\delta M$ plots suggests that the magnetostatic interactions are dominant [16, 17]. In Fig. 6, the $\delta M$ plots for all investigated ribbon specimens are shown. For samples annealed at $943 \mathrm{~K}$ and higher temperatures, the values of $\delta M$ is positive for applied magnetic fields smaller than the coercivity field. $\delta M$ reaches maximum around ${ }_{J} H_{\mathrm{c}}$. For higher magnetic fields $\delta M$ drops to zero and changes its sign, reaching negative maximum. The shapes of $\delta M(H)$ curves measured for ribbons annealed at $943 \mathrm{~K}$ and higher temperatures, suggest that the exchange interactions dominate for fields slightly higher than the coercivity field, while for higher $H$ the magnetostatic interactions are dominant. Only for the sample annealed at $923 \mathrm{~K}$ the values of $\delta M$ is initially negative until about $700 \mathrm{kA} / \mathrm{m}$. Then the $\delta M$ reaches positive maximum value in fields close to the coercivity and subsequently drops to zero. The experimental points for the sample annealed at $923 \mathrm{~K}$ indicate that the dominant interaction in lower applied reverse fields are the demagnetizing long range dipolar interactions between grains of hard magnetic phase. At the higher values of magnetic field the positive value $\delta M$ corresponds to exchange interactions stabilizing magnetization.

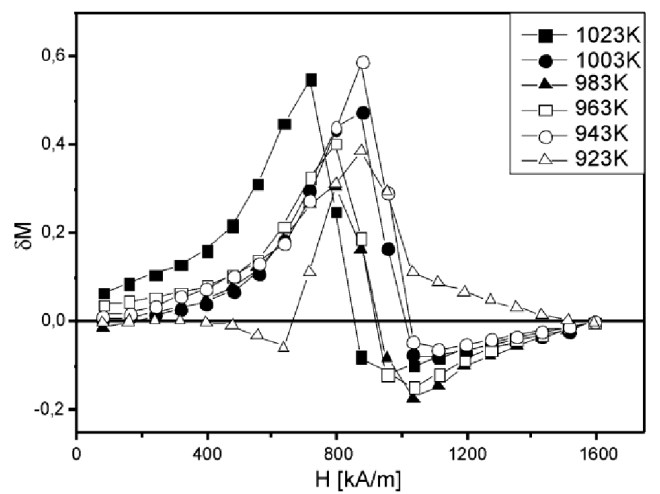

Fig. 6. The $\delta M$ plots for melt-spun $\mathrm{Pr}_{8} \mathrm{Dy}_{1} \mathrm{Fe}_{60} \mathrm{Co}_{7} \mathrm{Mn}_{6} \mathrm{~B}_{14} \mathrm{Zr}_{1} \mathrm{Ti}_{3}$ ribbons annealed in various temperatures for $5 \mathrm{~min}$.

\section{Conclusions}

The investigated $\operatorname{Pr}_{8} \mathrm{Dy}_{1} \mathrm{Fe}_{60} \mathrm{Co}_{7} \mathrm{Mn}_{6} \mathrm{~B}_{14} \mathrm{Zr}_{1} \mathrm{Ti}_{3}$ alloy ribbons in as-cast state had fully amorphous structure and exhibited soft magnetic properties. Subjecting the alloy to a heat treatment led to nucleation and growth of the hard and soft magnetic phases. With the increase 
of annealing temperature, no significant changes in the phase constitution, for all annealed samples was indicated. The application of short time annealing led to the improvement of the magnetic properties due to the change in their microstructure. The highest value of the maximum energy product $\left((B H)_{\max }=43.3 \mathrm{~kJ} / \mathrm{m}^{3}\right)$ and coercivity field $\left({ }_{\mathrm{J}} H_{\mathrm{c}}=925 \mathrm{kA} / \mathrm{m}\right)$ were measured for ribbons annealed at temperature $983 \mathrm{~K}$, but polarization remanence for this sample is the lowest from all measured specimens. For ribbons annealed at temperatures ranging from $943 \mathrm{~K}$ to $1023 \mathrm{~K}$ at low reverse fields the shortrange exchange interactions are dominant. In higher fields the $\delta M$ plot take negative values suggesting existence of long-range dipolar interactions between hard magnetic grains. In case of sample annealed at temperature $923 \mathrm{~K}$ reverse behavior was observed.

\section{References}

[1] M. Sagawa, S. Fujimura, N. Togawa, H. Yamamoto, J. Matsuura, J. Appl. Phys. 55, 2083 (1984).

[2] A. Manaf, R.A. Buckley, H.A. Davies, J. Magn. Magn. Mater. 128, 302 (1993).

[3] Y. Matsuura, J. Magn. Magn. Mater. 303, 344 (2006).

[4] Rare-Earth Iron Permanent Magnets, Ed. J.M.D. Coey, Oxford-Science, Oxford 1996.

[5] Ferromagnetic Materials, Eds. E.P. Wohlfarth, K.H.J. Buschow, Vol. 4, North-Holland, Amsterdam 1988.
[6] K. Pawlik, P. Pawlik, J.J. Wysłocki, W. Kaszuwara, J. Alloys Comp. 536S, S348 (2012).

[7] V. Neu, P. Crespo, R. Schäfer, J. Eckert, L. Schultz, J. Magn. Magn. Mater. 157/158, 61 (1996).

[8] M. Szwaja, P. Pawlik, J. Wysłocki, P. Gębara, Archiv. Metall. Mater. 57, 233 (2012).

[9] K. Filipecka, K. Pawlik, P. Pawlik, J.J. Wysłocki, P. Gębara, A. Przybył, Acta Phys. Pol. A 126, 164 (2014).

[10] A. Przybył, K. Pawlik, P. Pawlik, P. Gęara, J.J. Wyslocki, J. Alloys Comp. 536S, S333 (2012).

[11] Bai Yang, Bao-gen Shen, Tong-yun Zhao, Jirong Sun, J. Magn. Magn. Mater. 320, 2406 (2008).

[12] E.F. Kneller, R. Hawig, IEEE Trans. Magn. 27, 3588 (1991).

[13] H. Chiriac, M. Marinescu, P. Tiberto, F. Vinai, Mater. Sci. Eng. A 304-306, 957 (2001).

[14] P.E. Kelly, K. O'Grady, P.I. Mayo, R.W. Chantrell, IEEE Trans. Magn. 25, 3881 (1989).

[15] M. Fearon, R.W. Chantrell, E.P. Wohlfarth, J. Magn. Magn. Mater. 86, 197 (1990).

[16] K. O'Grady, M. El-Hilo, R.W. Chantrell, IEEE Trans. Magn. 29, 2608 (1993).

[17] I. Panagiotopoulos, L. Withanawasam, G.C. Hadjipanayis, J. Magn. Magn. Mater. 152, 353 (1996). 